\title{
Highly Ordered Amorphous Silicon-Carbon Alloys Obtained by RF PECVD
}

\author{
I. Pereyra, C. A. Villacorta, M.N.P. Carreño, \\ Depto. de Eng. Sistemas Eletrônicos, Escola Politécnica, \\ Universidade de São Paulo, São Paulo, Brasil \\ R.J. Prado, and M.C.A. Fantini \\ Instituto de Física, Universidade de São Paulo, São Paulo, Brasil \\ Received 15 February, 2000; received in final form on 29 March, 2000
}

\begin{abstract}
We have shown that close to stoichiometry RF PECVD amorphous silicon carbon alloys deposited under silane starving plasma conditions exhibit a tendency towards c-SiC chemical order. Motivated by this trend, we further explore the effect of increasing $\mathrm{RF}$ power and $\mathrm{H}_{2}$ dilution of the gaseous mixtures, aiming to obtain the amorphous counterpart of c-SiC by the RF-PECVD technique. Doping experiments were also performed on ordered material using phosphorus and nitrogen as donor impurities and boron and aluminum as acceptor ones. For nitrogen a doping efficiency close to device quality a-Si:H was obtained, the lower activation energy being $0,12 \mathrm{eV}$ with room temperature dark conductivity of $2.10^{-3}(\Omega . c m)$. Nitrogen doping efficiency was higher than phosphorous for all studied samples. For p-type doping, results indicate that, even though the attained conductivity values are not device levels, aluminum doping conducted to a promising shift in the Fermi level. Also, aluminum resulted a more efficient acceptor than boron, in accordance to observations in crystalline $\mathrm{SiC}$ material.
\end{abstract}

\section{Introduction}

The deposition of amorphous hydrogenated silicon carbide thin films, a- $\mathrm{Si}_{1-x} \mathrm{C}_{x}: \mathrm{H}$, by PECVD has been extensively studied due to the ability of this technique to control the carbon content in the films and, therefore, the optical gap $\left(E_{o}\right)$. The increase in the optical gap, following the increase in the carbon concentration, is desirable for many device strategies and has been one of the main appeals of these alloys. However, for high carbon content films $(x \sim 0.5)$, a decrease in the optical gap is generally observed, which leads to a difficulty in obtaining a material with $E_{o}>2,5-3 \mathrm{e} \mathrm{V}$ [1]. This decrease in the optical gap observed for carbon rich a- $\mathrm{Si}_{1-x} \mathrm{C}_{x}: \mathrm{H}$ has been related to the existence of graphite-like $s p^{2} \mathrm{C}-\mathrm{C}$ bonding instead of diamond-like $s p^{3}$ C-C bonding [1,2].

Solomon and co-workers [3] showed that in the low power regime, where the RF power is sufficient to break the $\mathrm{SiH}_{4}$ molecules but not the $\mathrm{CH}_{4}$ ones, the presence of graphite-like bonds is avoided. However the carbon to silicon relative concentration in the solid phase is limited up to $50 \%$ and the resulting material is rich in methylated radicals. Recently, we have demonstrated that it is possible to obtain non methylated PECVD a$\mathrm{SiC}: \mathrm{H}$ thin films (from $\mathrm{SiH}_{4}+\mathrm{CH}_{4}$ ) with carbon to sili- con ratio higher than 0.5 (up to 0.7) with C-C bonds occurring mainly in the $s p^{3}$ (diamond-like) hybridization, optical gap as high as $3.7 \mathrm{eV}$ and high electrical resistivity [4-6]. The results demonstrate that these diamondlike silicon carbide films are obtained in a special deposition condition, called "silane starving plasma" regime [6]. This regime is a particular case of the low power density one where, for a critically low $\mathrm{SiH}_{4}$ flow, the film growth is controlled by the spare $\mathrm{SiH}_{4}$ radicals, simplifying the plasma chemistry and promoting carbon incorporation in the $s p^{3}$ hybridization. In this way we have shown that the starving plasma deposition conditions have a crucial role in the growth of close to stoichiometry material exhibiting a tendency towards the chemical order of crystalline silicon carbide, this is to say each silicon atom (tetrahedrally) bonded to four carbon atoms and each carbon atom bonded to four silicon atoms. For carbon rich samples this deposition regime promotes the production of films with very high values of the optical gap, strongly suggesting the incorporation of carbon in $s p^{3}$ bonds.[1]

Chemical order in silicon carbon alloys has been a controversial point. Cardona et. al. in their pioneering work [7], and many authors after them, argued that silicon and carbon atoms are randomly distributed, with no preferential hetero-nuclear $(\mathrm{Si}-\mathrm{C})$ bonds. On 
the other hand, Evangelisti et al.[8] have reported a strong tendency towards the chemical order of c-SiC in a-Si ${ }_{1-x} \mathrm{C}_{x}: \mathrm{H}$ films. Our work indicates that material grown in the low power regime out of silane starving conditions are silicon rich randomly distributed while the material grown with silane starving plasma conditions is close to stoichiometry or carbon rich and exhibits a preference for hetero-nuclear bonding ( $\mathrm{SiC}$ chemical order).

Encouraged by the chemical order exhibited by a$\mathrm{Si}_{1-x} \mathrm{C}_{x}: \mathrm{H}$ alloys produced in the silane starving regime we further explore the possibility of increasing even more the chemical order to promote the growth of an amorphous counterpart of c-SiC or even $\mathrm{SiC}$ microcrystals $(\mu-\mathrm{SiC})$. We also analyze the $n$ and $p$ type doping efficiency of these $\mathrm{a}-\mathrm{Si}_{1-x} \mathrm{C}_{x}: \mathrm{H}$ films.

It is known that hydrogen etching during the growth of amorphous silicon has a very important effect on the structural properties of a-Si:H films [9] and $\mathrm{H}_{2}$ dilution of the gas mixture is a technique widely used to produce microcrystalline $\mathrm{Si}$. In this way, some authors have used hydrogen dilution and higher RF power density to produce microcrystalline $p$-type silicon carbon (boron doped) alloys. In fact they obtained silicon micro-crystals embedded in an hydrogenated amorphous silicon carbon alloy network $[10,11]$. At the present time, to our knowledge, there is no report of $\mathrm{SiC}$ micro-crystals obtained by RF-PECVD which justifies our interest in pursuing this task taking advantage of the promising properties of the $\mathrm{a}-\mathrm{SiC}: \mathrm{H}$ obtained in silane starving plasma conditions.

Similarly, the structural order in $\mathrm{a}-\mathrm{SiC}: \mathrm{H}$ grown in "silane starving plasma" regime is a very important characteristic for doping experiments, since it is an universal fact that amorphous silicon based alloys exhibit an enhanced degree of disorder for increasing alloy element content, which decreases the carrier mobility and prevents the occurrence of an efficient doping, limiting their device applications. In this way we study the influence of the chemical order, induced by the "starving plasma" condition on the $n$-type and $p$-type doping efficiency of PECVD a-Si ${ }_{1-x} \mathrm{C}_{x}: \mathrm{H}$.

\section{Experimental details}

a- $\mathrm{Si}_{1-x} \mathrm{C}_{x}: \mathrm{H}$ films were prepared by the radio frequency (RF) Plasma Enhanced Chemical Vapor Deposition (PECVD) technique, with an RF frequency of 13,56 $\mathrm{MHz}$, from appropriated gaseous mixtures of $\mathrm{SiH}_{4}+$ $\mathrm{CH}_{4}+\mathrm{H}_{2}$ in a capacitively coupled reactor. A more detailed description of the deposition system can be found elsewhere [12]. RF power density, methane concentration, and hydrogen dilution of the gaseous mixtures were varied. Substrate temperature for all the samples was $300{ }^{\circ} \mathrm{C}$ and silane flow was kept at the minimum value $(3 \mathrm{sccm})$ in order to guarantee the "starving regime".

To establish the role of the "starving plasma" in the doping efficiency of a-SiC:H, the first experiments were carried out to compare the performance of samples grown in and out of this condition. For this purpose, both types of samples were ion-implanted with $3 \cdot 10^{20} \mathrm{~cm}^{-3}$ phosphorous and nitrogen. More details on the ion-implantation are reported elsewhere [13].

Based on the results obtained for samples grown with $\mathrm{H}_{2}$ dilution of the gaseous mixture and on n-type doping, in case of the $p$-type doping experiments we centered on samples grown in "silane starving plasma" with $\mathrm{H}_{2}$ dilution. Since good results in crystalline $\mathrm{SiC}$ have been obtained with aluminum, we utilized this doping element as acceptor impurity. However this impurity had to be introduced in the films through low temperature thermal diffusion experiments due to technical difficulties with the aluminum ion implantation. Aluminum diffusion was carried out by thermally evaporating a thin aluminum layer followed by a thermal annealing step. The analyzed annealing steps were 350 ${ }^{\circ} \mathrm{C}$ for 4,8 and 12 hours and $450{ }^{\circ} \mathrm{C}$ for $0,5,2,4$ and 6 hours.

The films structure and bonding were characterized by Fourier transform infrared (FTIR) spectroscopy, optical absorption and extended X-ray absorption fine structure (EXAFS). The atomic concentrations of Si, $\mathrm{C}, \mathrm{N}$ and $\mathrm{P}$ were determined by Rutherford backscattering (RBS) using a $2.3 \mathrm{MeV} \mathrm{He}{ }^{+}$beam, with scattering angle of $170^{\circ}$. The $\mathrm{H}$ content was determined through forward recoil spectrometry (FRS) with a target tilt angle of $75^{\circ}$ and $30^{\circ}$ detection angle. The transport properties of doped samples were studied analyzing the thermal dependence of the dark conductivity, $\sigma_{d}(T)$, measured in a vacuum cryostat. The thermal activation energy $\left(E_{a}\right)$ was determined from the Arrhenius plot. In those plots the data were fitted with a function $\ln \left[\sigma_{d}(T)\right]=A+B / T$ and the activation energy was obtained from the slopes of those functions. The reproducibility of these results lead to an estimated error less than $10 \%$ for the conductivity. A $10 \%$ error for the activation energy was obtained by comparison of the maximum and minimum slopes in the Arrhenius plot.

\section{Results and discussion}

\section{III.1. $\mathrm{H}_{2}$ Dilution and $\mathrm{RF}$ power}

Fig. 1 shows the optical gap $E_{o}$ as a function of $\mathrm{CH}_{4}$ concentration for samples grown under starving plasma conditions with and without hydrogen diluted gaseous mixtures. It is observed that for samples grown without $\mathrm{H}_{2}$ dilution the optical band gap increases slowly for $\mathrm{CH}_{4}$ concentration values up to around $77 \%$, while for higher concentration values it increases abruptly up to values higher than $3 \mathrm{eV}$. Samples deposited with 
$\mathrm{H}_{2}$ dilution show a similar but more pronounced behavior, the transition occurring at higher values of the $\mathrm{CH}_{4}$ concentration (approximately 88\%). This transition is associated with the passage over the stoichiometric composition $(x=0.5)$, so these results suggest a lower carbon incorporation in the solid phase for hydrogen diluted deposited material.

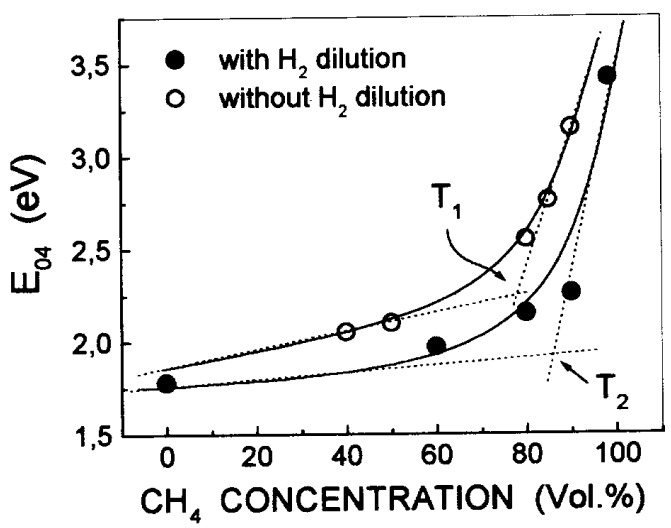

Figure 1. Optical gap as a function of the methane concentration for samples deposited at a RF power density of $25 \mathrm{~mW} / \mathrm{cm}^{2}$ and with a $\mathrm{H}_{2}$ flow of $100 \mathrm{sccm}(\bullet)$ and without $\mathrm{H}_{2}$ dilution (o).

In Fig. 2 the integrated absorption of the IR absorption peak at $780 \mathrm{~cm}^{-1}$, assigned to the $\mathrm{Si}-\mathrm{C}$ stretching vibrations [1], divided by the sample thickness as function of methane volume fraction is depicted, for the same samples in Fig. 1. A maximum in the integrated absorption is observed for both sets of samples. However the peak position is shifted towards higher $\mathrm{CH}_{4}$ concentrations for the $\mathrm{H}_{2}$ diluted samples. Actually this maximum is an indication that the stoichiometric concentration $x=0.5$ has been passed through, since for higher carbon content the density of $\mathrm{Si}-\mathrm{C}$ bonds should decrease and the $\mathrm{C}-\mathrm{C}$ bonds should increase. In this way this result indicates, in accordance with the RBS measurements and the optical gap results, that stoichiometry is attained for higher $\mathrm{CH}_{4}$ concentrations for samples deposited with $\mathrm{H}_{2}$ diluted gas mixtures. For samples prepared at $25 \mathrm{~mW} / \mathrm{cm}^{2}$ and with $\mathrm{H}_{2}$ dilution no traces, within the detection limit of $\sim 1 \%$ of the FTIR technique, of $\mathrm{CH}_{n}$ bonds are observed. The concentration of $\mathrm{SiH}_{n}$ is also lower than in films grown without $\mathrm{H}_{2}$ dilution and becomes very small for a $\mathrm{CH}_{4}$ concentration of $98 \%$. This means that for increasing $\mathrm{C}$ content in the solid phase, the polymeric phase always present in the hydrogenated amorphous silicon carbon alloys has been almost eliminated by the "etching process" and very low hydrogen content is obtained.

Having identified the methane concentration leading to close to stoichiometry material for hydrogen diluted gaseous mixtures and a RF power of $25 \mathrm{~mW} / \mathrm{cm}^{2}$, we chose this condition to perform our studies on the effect of increasing $\mathrm{H}_{2}$ dilution and $\mathrm{RF}$ power densities on the structural properties of the films.

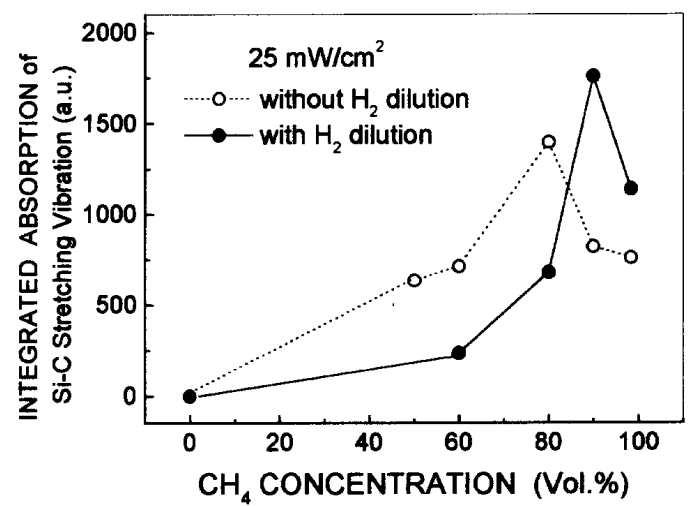

Figure 2. Integrated absorption intensity for the $\mathrm{Si}-\mathrm{C}$ bond vibration peak vs. methane concentration for samples deposited at a RF power density of $25 \mathrm{~mW} / \mathrm{cm}^{2}$ with a $\mathrm{H}_{2}$ flow of $100 \mathrm{sccm}(\bullet)$ and without $\mathrm{H}_{2}$ dilution (o).

In Table 1 the RBS results are summarized. It is observed that increasing RF power increases the carbon content and decreases the hydrogen concentration of the films, increasing hydrogen flow decreased the hydrogen content even further.

Table 1: Composition of the studied samples obtained from RBS measurements.

\begin{tabular}{|c|c|c|c|c|c|}
\hline $\begin{array}{c}\text { Power } \\
\text { density } \\
\left(\mathbf{m W} / \mathrm{cm}^{2}\right)\end{array}$ & $\begin{array}{c}\mathbf{H}_{\mathbf{2}} \text { flow } \\
(\mathbf{s c c m})\end{array}$ & $\begin{array}{c}\mathbf{H} \\
(\mathbf{a t .} \%)\end{array}$ & $\begin{array}{c}\mathbf{C} \\
(\mathbf{a t .} \%)\end{array}$ & $\begin{array}{c}\text { Si } \\
(\mathbf{a t .} \%)\end{array}$ & $\mathbf{x}$ \\
\hline 50 & 0 & 0.54 & 0.28 & 0.15 & 0.64 \\
\hline 12.5 & 100 & 0.33 & 0.26 & 0.34 & 0.32 \\
\hline 50 & 100 & 0.33 & 0.26 & 0.36 & 0.35 \\
\hline 75 & 100 & 0.27 & 0.36 & 0.34 & 0.46 \\
\hline 125 & 100 & 0.26 & 0.38 & 0.33 & 0.49 \\
\hline 12.5 & 200 & 0.20 & 0.28 & 0.44 & 0.32 \\
\hline 12.5 & 300 & 0.20 & 0.28 & 0.42 & 0.35 \\
\hline
\end{tabular}

The FTIR spectra for samples grown with different $\mathrm{H}_{2}$ flow, depicted in Fig. 3 show an enhanced absorption band at $780 \mathrm{~cm}^{-1}$. Since the sample deposited without hydrogen dilution and $90 \%$ methane volume concentration is carbon rich as indicated by the RBS measurements [14] the increase in the Si-C band can be attributed to the fact that the samples are getting closer to stoichiometry, indicating that the $\mathrm{H}_{2}$ etching process 
attacks preferentially carbon bonds. This hypothesis is confirmed by RBS measurements, which show that the $\mathrm{Si} / \mathrm{C}$ ratio increases for increasing $\mathrm{H}_{2}$ dilution. At the same time, the $\mathrm{CH}_{n}$ and the $\mathrm{Si}-\mathrm{CH}_{n}$ stretching vibration absorption bands (in the $2800 \mathrm{~cm}^{-1}$ to $3000 \mathrm{~cm}^{-1}$ and 1250 to $1350 \mathrm{~cm}^{-1}$ spectral regions, respectively) decrease and for $\mathrm{H}_{2}$ flow higher than $100 \mathrm{sccm}$ and the $\mathrm{CH}_{n}$ related bands disappear which is also consistent with the hypothesis of preferential carbon etching. The FTIR spectra also show a pronounced decrease in the $\mathrm{H}$ content of the films for increasing $\mathrm{H}_{2}$ flow, revealed by the $\mathrm{CH}_{n}$ and $\mathrm{SiH}_{n}$ bonding configurations. It is also observed that the $\mathrm{Si}-\mathrm{H}$ stretching absorption band located at $2090 \mathrm{~cm}^{-1}$, decreases but it does not disappear as the $\mathrm{CH}_{n}$ bands, which is consistent with the hypothesis of preferential etching of the $\mathrm{C}-\mathrm{H}$ bonds.

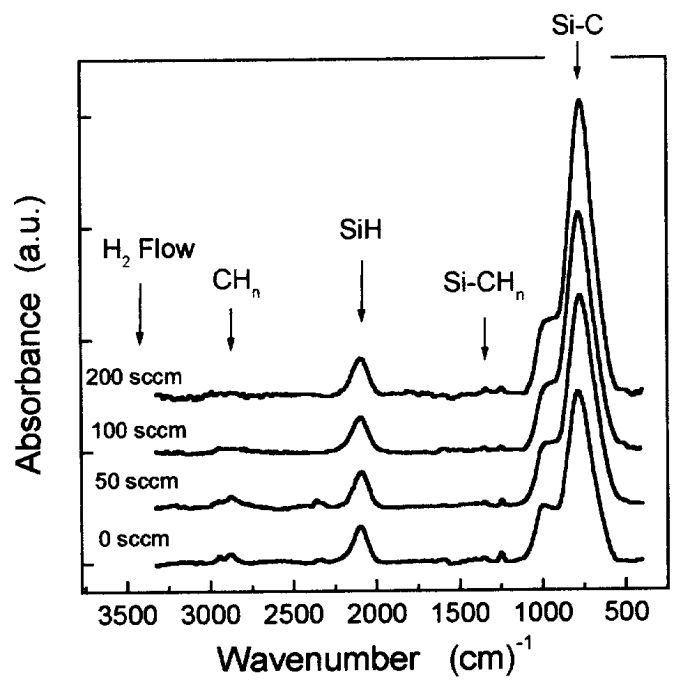

Figure 3. Infrared spectra for samples deposited with a RF power density of $25 \mathrm{~mW} / \mathrm{cm}^{2}, 90 \%$ methane volume fraction and varying $\mathrm{H}_{2}$ flow.

In order to study the effect of increasing RF power densities a sample set, varying the RF power density between 12,5 and $500 \mathrm{~mW} / \mathrm{cm}^{2}$ and keeping constant all the other deposition parameters, was prepared. It was also found that, as the RF power density increases, the deposition rate increases. This result indicates that for higher RF power the deposition mechanism increases more rapidly than the etching one. In Fig. 4 an increase in the Si-C absorption band for increasing $\mathrm{RF}$ power densities, up to $250 \mathrm{~mW} / \mathrm{cm}^{2}$, is observed. However further increase up to $500 \mathrm{~mW} / \mathrm{cm}^{2}$ decreases the amplitude of this band. This result is interpreted as due to an increasing carbon concentration in the samples. For low RF power the samples are silicon rich while for high RF power carbon rich samples are obtained. The maximum in the Si-C absorption band obtained for 250 $\mathrm{mW} / \mathrm{cm}^{2}$ indicates that for these deposition parameters very close to stoichiometry material is produced. The observed increase in the carbon content of the samples, also supported by the RBS measurements and by the increasing $\mathrm{CH}_{n}$ related bands, indicates that for high $\mathrm{RF}$ power the etching mechanism is less efficient in extracting the $\mathrm{C}-\mathrm{H}$ bonds. This last result is consistent with the observed increase in the deposition rate.

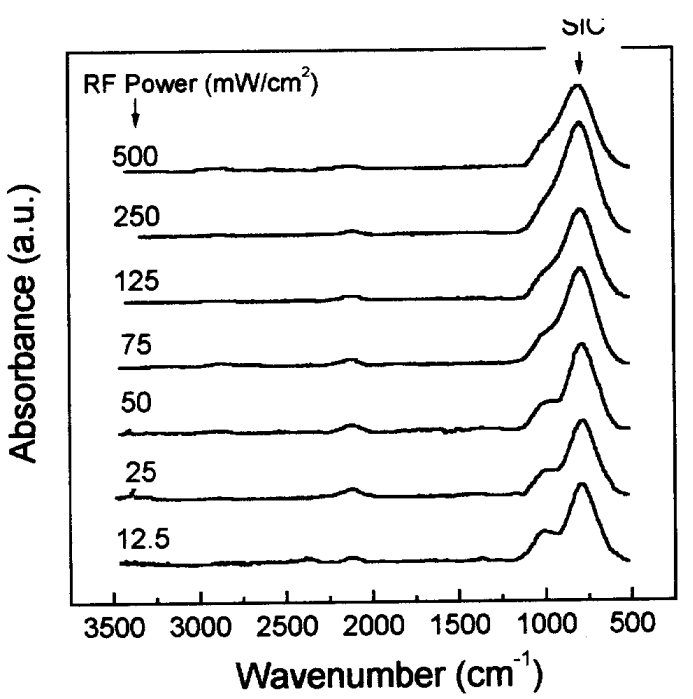

Figure 4. Infrared spectra for samples deposited with a $\mathrm{H}_{2}$ flow of $100 \mathrm{sccm}, 90 \%$ methane volume fraction and varying the RF power density.

From the EXAFS data at the Si K edge it was possible to analyze the short range structural and chemical order of the films. Assuming that the material is a binary alloy, composed of $\mathrm{Si}$ and $\mathrm{C}$ atoms, which is valid due to the low oxygen contamination $(\sim 1 \%$ $3 \%$ ), the coordination of carbon atoms with silicon was estimated [15].

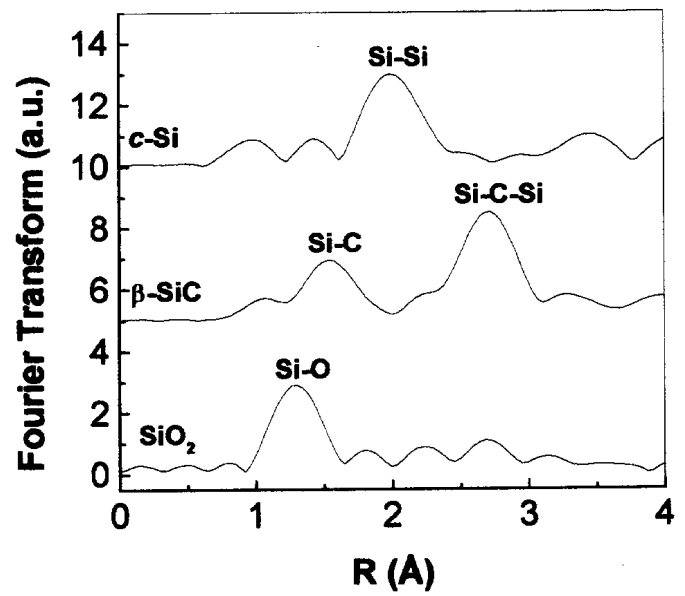

Figure 5. Fourier transform of the EXAFS spectra for the reference samples.

Fig. 5 presents the Fourier transform of the EXAFS spectra for the reference samples $\left(\mathrm{SiO}_{2}, \mathrm{c}-\mathrm{Si}\right.$ and 
$\beta$-SiC), showing the characteristic peaks. Due to the phase-shift, the apparent bonding distances are about $1.15 \AA$ for $\mathrm{Si}-\mathrm{O}, 1.6 \AA$ for $\mathrm{Si}-\mathrm{C}$ and $2.0 \AA$ for $\mathrm{Si}-\mathrm{Si}$.
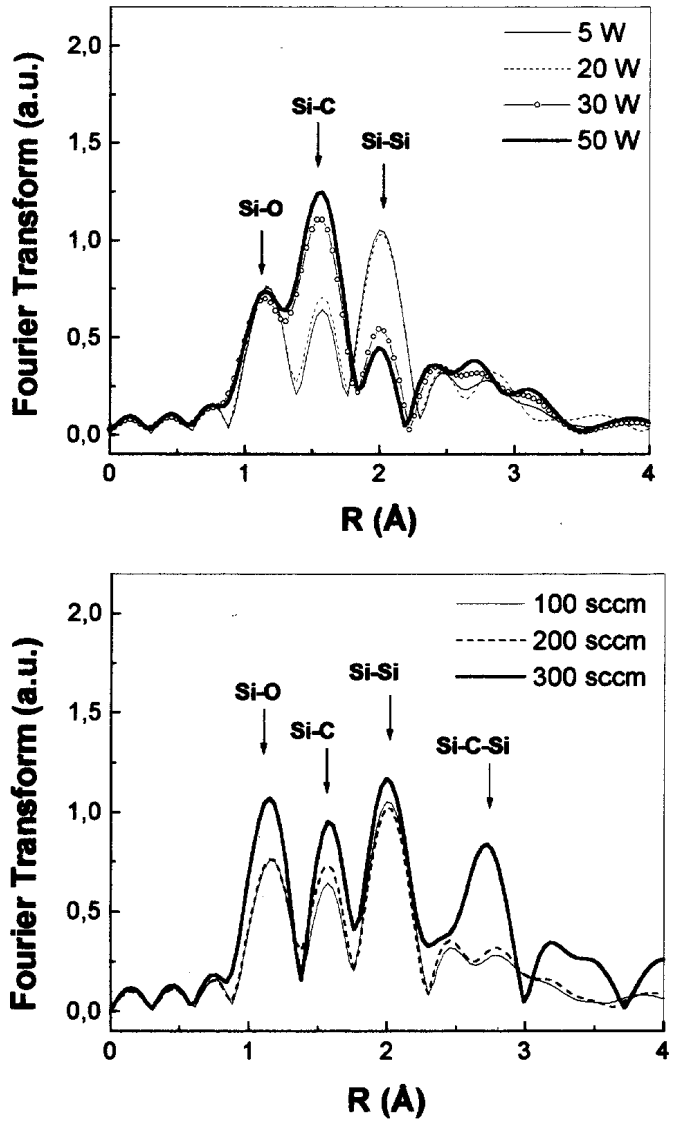

Figure 6. Fourier transform for (a) the power variation series and (b) the $\mathrm{H}_{2}$ dilution variation series.

Fig. 6a shows the Fourier transform of the EXAFS spectra of the samples grown with different RF power. It is observed that samples grown with higher RF power exhibit a larger area under the peak associated to the $\mathrm{Si}-\mathrm{C}$ coordination. Fig. $6 \mathrm{~b}$ shows the Fourier transform of the EXAFS spectra of samples deposited under different $\mathrm{H}_{2}$ dilution, at low $\mathrm{RF}$ power density $\left(12.5 \mathrm{~mW} / \mathrm{cm}^{2}\right)$. The data reveal that the sample deposited at the highest $\mathrm{H}_{2}$ dilution (300 sccm) presents a medium range order structure, with distances greater than $3 \AA$, related to the second coordination shell.

The coordination for the Si-C bond increased for increasing RF power from 1.65 , for sample deposited at $12.5 \mathrm{~mW} / \mathrm{cm}^{2}$, to 2.8 for the sample deposited at 125 $\mathrm{mW} / \mathrm{cm}^{2}$. For all samples the total Si coordination was greater than 3.5

\section{III.2. Doping}

The electrical measurements on $n$-type doped samples confirm that the "starving plasma" condition has a very important effect on the doping properties of a$\mathrm{SiC}: \mathrm{H}$. Fig. 7 shows the Arrhenius plots for samples grown in "starving" and "non-starving" plasma condition and implanted with $3.10^{20} \mathrm{~cm}^{-3}$ nitrogen and phosphorus.

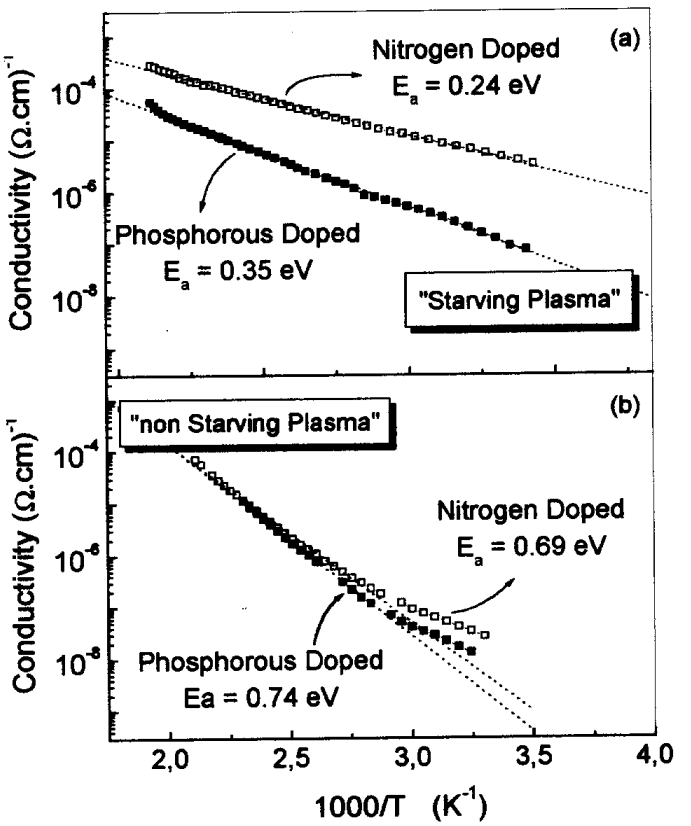

Figure 7. Arrhenius plots for nitrogen and phosphorous doped sample grown in (a) "starving" plasma condition and (b) "non-starving" plasma condition. In both cases the impurity concentrations is $10^{20} \mathrm{~cm}^{-3}$.

It is observed that the sample obtained in "starving plasma" shows an activation energy of $0.24 \mathrm{eV}$, which is not only a low value but 3 times lower than the exhibited by the sample grown in "non-starving plasma" conditions. Note that this behavior is observed for both doping elements, phosphorus and nitrogen, and that nitrogen appear as a much more efficient doping impurity than phosphorus.

The results for samples grown in the silane starving plasma condition and implanted with $10^{20}$ and $10^{21}$ $\mathrm{cm}^{-3}$ nitrogen and phosphorous are depicted in Fig. 8 . For comparison the electrical conductivity for intrinsic a-SiC:H is included. As we can see, the results for an impurity concentration of $10^{21} \mathrm{~cm}^{-3}$ are very encouraging, presenting an activation energy as low as 0.12 $\mathrm{eV}$ and room temperature dark conductivity in the order of $10^{-3}(\Omega . c \mathrm{~m})^{-1}$. It should be pointed out that 
the "starving plasma" condition improves the $n$-type doping efficiency of the films up to levels close to those obtained in device quality a-Si:H.

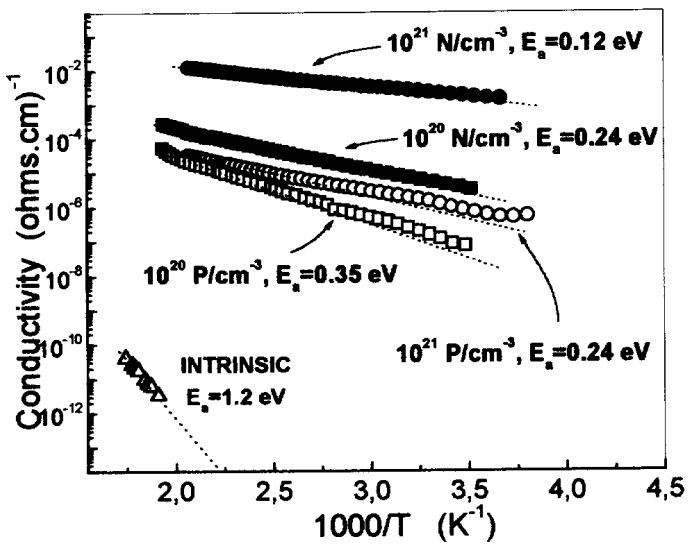

Figure 8. N-type doping: Arrhenius plot for stoichiometric samples grown in "starving plasma" condition implanted with $10^{20}$ and $10^{2 l} \mathrm{~cm}^{-3}$ nitrogen (solid symbol) and phosphorus (open symbol).

Table 2: Room temperature electrical conductivity $\left(\sigma_{R T}\right)$, conductivity therrnal activation energy $\left(E_{a}\right)$ and the optical $\left(E_{o}\right)$ for the $\mathrm{Al}$ diffused samples.

\begin{tabular}{|c|c|c|c|}
\hline $\begin{array}{c}\text { Diffusion } \\
\text { Process }\end{array}$ & $\begin{array}{c}\sigma_{\mathrm{RT}} \\
(\Omega . \mathrm{cm})^{-1}\end{array}$ & $\begin{array}{c}\mathrm{E}_{\mathrm{a}}(\mathrm{eV}) \pm \\
0.05\end{array}$ & $\begin{array}{c}\mathrm{E}_{\mathrm{o}}(\mathrm{eV}) \pm \\
0.2\end{array}$ \\
\hline Intrinsic & $<10^{-15}$ & 1,2 & 2,6 \\
\hline $350{ }^{\circ} \mathrm{C}, 4 \mathrm{~h}$ & $\sim 5 \times 10^{-15}$ & 0.86 & 2,6 \\
\hline $350{ }^{\circ} \mathrm{C}, 8 \mathrm{~h}$ & $\sim 5 \times 10^{-15}$ & 0.9 & 2,6 \\
\hline $350{ }^{\circ} \mathrm{C}, 12 \mathrm{~h}$ & $\sim 5 \times 10^{-15}$ & 0.8 & 2,6 \\
\hline Intrinsic & $<10^{-15}$ & 1.1 & 2.6 \\
\hline $450^{\circ} \mathrm{C}, 2 \mathrm{~h}$ & $3 \times 10^{-12}$ & 0.39 & - \\
\hline $450^{\circ} \mathrm{C}, 4 \mathrm{~h}$ & $8 \times 10^{-12}$ & 0.35 & - \\
\hline $450^{\circ} \mathrm{C}, 6 \mathrm{~h}$ & $3 \times 10^{-11}$ & 0.38 & - \\
\hline $450^{\circ} \mathrm{C}, 6 \mathrm{~h}$ & $10^{-7}$ & 0.17 & - \\
\hline
\end{tabular}

Also, it is observed that sample doped with $10^{21}$ $\mathrm{cm}^{-3}$ phosphorus has almost the same activation energy than sample doped with $10^{20} \mathrm{~cm}^{-3}$ nitrogen, but exhibits a conductivity significantly lower, indicating that the mobility for nitrogen doped samples is higher.
As it can be appreciated in Table 2, the aluminum diffusion had a clear effect in the transport characteristics of the samples. It is also observed that the optical gap remained unchanged for all samples. The Arrhenius plot for the aluminum diffused samples is depicted on Fig. 9.

As we can see, the doping was effective, leading to an activation energy of $\sim 0,2 \mathrm{eV}$ in the best case, which is very low if we consider that the energy gap of the samples is $2,4 \mathrm{eV}$ and that we are dealing with an amorphous alloy, where it is normally difficult to shift the Fermi level position. Despite the low activation energy, the electrical conductivity remains quite low, being $\sim 10^{-7}(\Omega . \mathrm{cm})^{-1}$ at room temperature and $\sim 10^{-6}(\Omega . \mathrm{cm})^{-1}$ at $570 \mathrm{~K}$. Probably this fact is related with a non-ohmic character of the metal contacts. It is known that obtaining good ohmic contacts to p-type $\mathrm{SiC}$ is a very difficult task, even for crystalline material, and specially for lower doping concentrations. This problem makes difficult to obtain reproducible results, specially for the absolute value of the dark conductivity, since the contribution of the contact resistance is not well evaluated. It is important to recall here that, in general, the task of high conductive p-type doping and confident metal contacts to crystalline $\mathrm{SiC}$ has not yet been solved [16]. In this way, the results reported here with $\mathrm{Al}$ doping are very promising.

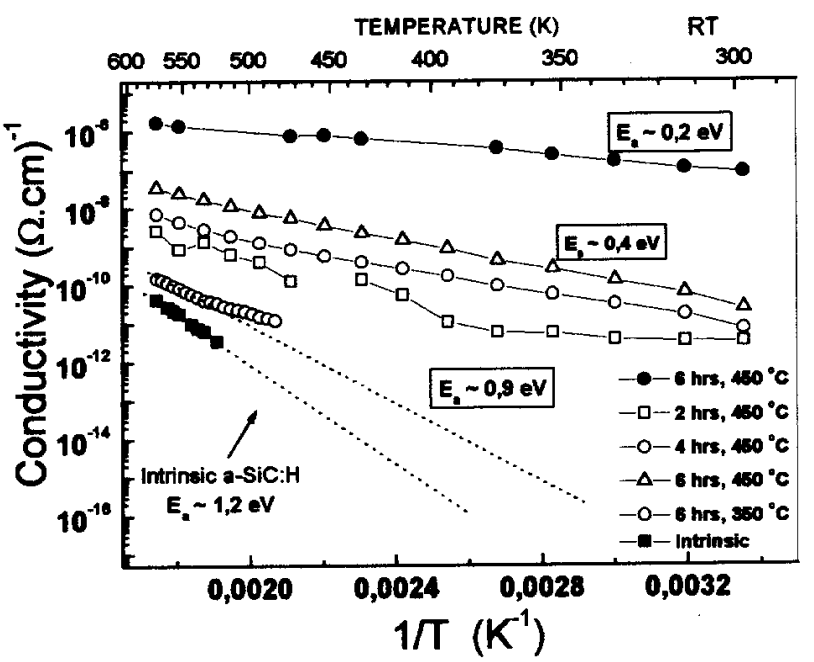

Figure 9. Conductivity vs. $1 / \mathrm{T}$ for intrinsic and $\mathrm{Al}$ doped samples. The data are fitted with functions $\ln \sigma=A^{i}+$ $B^{i} / T$ where $i$ is $\square, \circ, \bullet, \boldsymbol{\square}$. The activation energies are the slopes of those functions.

\section{Conclusions}

The results obtained for silicon carbon alloys have indicated the way to produce a highly ordered material and the trend to obtain microcrystalline SiC by PECVD. 
This fact is well illustrated in Fig. 10 which shows the FTIR spectrum for a sample crystallized at $1200{ }^{\circ} \mathrm{C}$ (crystallized $\mathrm{SiC}$ sample) together with the spectra of three close to stoichiometry a-SiC:H as deposited samples, grown in the following conditions: (a) out of the "silane starving regime" ("non-starving" sample), (b) in "silane starving" conditions ("starving" sample) and (c) in "silane starving" conditions with hydrogen diluted gas mixture ("starving" $+\mathrm{H}_{2}$ sample). It is observed that the crystallized sample exhibits a single peak spectrum, just one band at $800 \mathrm{~cm}^{-1}$, corresponding to $\mathrm{Si}-\mathrm{C}$ vibrations. The "starving" $+\mathrm{H}_{2}$ sample exhibits a large Si-C stretching band and a very small $\mathrm{Si}-\mathrm{H}$ stretching band. In fact, the spectrum is very close to that of the crystallized sample, the main difference being the full width at half maximum, due to the structural disorder. This indicates that the short range order of our material is very similar to crystalline $\mathrm{SiC}$, in other words, we have attained our goal of producing the amorphous counterpart of $\mathrm{c}-\mathrm{SiC}$.

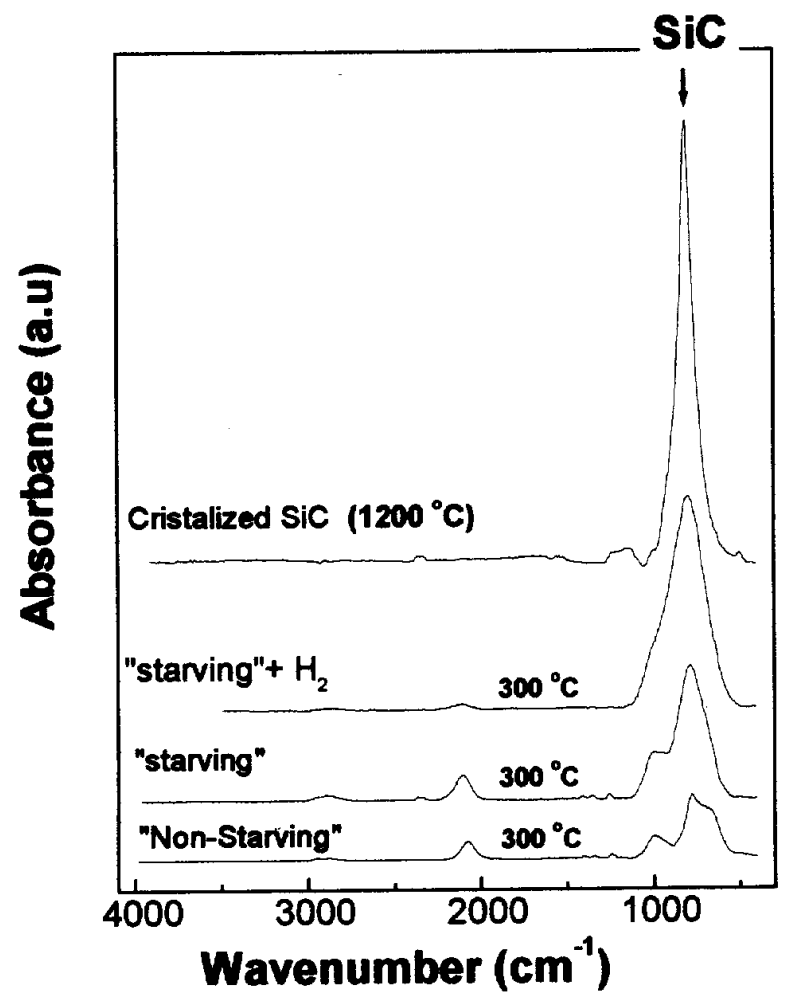

Figure 10. FTIR spectra for 3 as deposited samples (300 ${ }^{\circ} \mathrm{C}$ ) and one thermally crystallized at $1200^{\circ} \mathrm{C}$.

On the other hand, the "non-starving" sample presents just a small $\mathrm{SiC}$ peak and exhibits quite large bands corresponding to $\mathrm{Si}-\mathrm{H}_{n}\left(640\right.$ and $\left.2090 \mathrm{~cm}^{-1}\right)$ and $\mathrm{Si}-\mathrm{CH}_{3}$ vibrations $\left(1250 \mathrm{~cm}^{-1}\right)$. On the contrary, the "starving" sample already presents the main features of silicon carbide materials, this is to say a large SiC stretching band, but still presents a large band due to $\mathrm{Si}-\mathrm{H}_{n}$ bonds and some $\mathrm{Si}-\mathrm{CH}_{3}$ vibrations, the $\mathrm{CH}_{n}$ vibrations in the $2900 \mathrm{~cm}^{-1}$ spectral region are also apparent.

These FTIR results are corroborated by the EXAFS experiments which lead to an increased coordination number for $\mathrm{Si}-\mathrm{C}$ bonds for higher $\mathrm{RF}$ power densities, signature of a higher degree of short range order. In this way it was demonstrated that conventional PECVD technique can be used successfully to produce amorphous silicon carbon alloys with excellent structural properties provided that a set of deposition parameters, which enable to control the plasma chemistry, are established.

It was also shown that the "starving plasma" condition has indeed an important role in increasing the $n$-type doping efficiency of PECVD produced a-SiC:H since a sample implanted with a nitrogen dose of $10^{20}$ $\mathrm{cm}^{-3}$ grown in "non-starving" conditions showed an activation energy much higher than a "starving" produced sample implanted with the same dose. Furthermore, for a sample grown in this condition, activation energy and dark conductivity values comparable to device quality a-Si:H were obtained. It is also demonstrated that nitrogen doping is more efficient than phosphorus doping for these a-Si $i_{1-x} \mathrm{C}_{x}$ alloys. The experiments with low temperature thermal diffusion of $\mathrm{Al}$ resulted in a very promising shift of the Fermi level. The electrical conductivity however, must be increased and for this purpose it is important to prepare ohmic contacts and decrease the contact resistivity.

\section{Acknowledgements}

The authors are grateful to Dr. M.H. Tabanicks for the RBS and FRS measurements. This work was partially supported by the Brazilian agencies: FAPESP, CNPq and CAPES.

\section{References}

[1] J. Bullot and M.P. Schmidt, Phys. Stat. Sol. (b) 143, 345 (1987).

[2] R. S. Sussman and R. Odgen, Phil. Mag. B 44, 137 (1981).

[3] I. Solomon, M. P. Schmidt and H. Tran-Quoc, Phys. Rev. B 38, 9895 (1988).

[4] V. Mastelaro, A.M. Flank, M.C.A. Fantini, D.R. Bittencourt, M.N.P. Carreño and I. Pereyra, J. Appl. Phys. 79, 1324 (1996).

[5] I. Pereyra and M.N.P. Carreño, Journal of Non-Cryst. Solids 201, 110 (1996).

[6] I. Pereyra, M.N.P. Carreño, R.J. Prado, D.R.S. Bittencourt, M.H. Tabacniks and M.C.A. Fantini, J. Appl. Phys. 84, 2371 (1998). 
[7] H. Wieder, M. Cardona and C.R. Guarnieri, Phys. Status Solidi B 92, 99 (1979).

[8] F. Evangelisti, J. of Non-Cryst. Sol. 164-166, 1009 (1993).

[9] C.C. Tsai, G.B. Anderson and R.Thompson, Mat. Res. Soc. Symp. Proc. 192, 475 (1990).

[10] Y. Hamakawa, D. Kruangam, T. Toyama, H. Yoshimi, S. Paasche and H. Okamoto, Optoelectronics 4, 281 (1989).

[11] G. Ganguly, S. C. DE, Swati Ray and A. K. Barua, J. of Non-Crys. Sol. 114, 822 (1989).
[12] M.N.P. Carreño, J.P. Bottecchia, I. Pereyra, Thin Solid Films 308-309, 219 (1997).

[13] M.N.P. Carreño, I. Pereyra and H.E.M. Peres, J. of Non-Cryst. Sol. 227-230, 483 (1998).

[14] R.J. Prado, D.R.S. Bittencourt, M.H. Tabackniks, M.C.A. Fantini, M.N.P. Carreño and I. Pereyra, J. Appl. Cryst. 30, 659 (1997).

[15] G.S. Cargill III and F. Spaepen, J. of Non-Cryst. Solids 43, 91 (1981).

[16] J. Crofton, L.M. Porter and J.R. Williams, Phys. Stat. Sol. (b) 202, 581 (1997). 